This item was submitted to Loughborough's Research Repository by the author.

Items in Figshare are protected by copyright, with all rights reserved, unless otherwise indicated.

\title{
Spatial mapping of building energy demand in Great Britain
}

PLEASE CITE THE PUBLISHED VERSION

http://dx.doi.org/10.1111/gcbb.12165

PUBLISHER

(c) John Wiley \& Sons Ltd

VERSION

SMUR (Submitted Manuscript Under Review)

LICENCE

CC BY-NC-ND 4.0

REPOSITORY RECORD

Taylor, Simon, Steven K. Firth, David Allinson, Mohammed A. Quddus, Chao Wang, and Pete Smith. 2019. "Spatial Mapping of Building Energy Demand in Great Britain". figshare. https://hdl.handle.net/2134/14179. 


\title{
Spatial mapping of building energy demand in Great Britain
}

\section{Running title: Mapping of building energy demand}

\author{
Simon C. Taylor ${ }^{1}$, Steven K. Firth ${ }^{1}$, Chao Wang ${ }^{2}$, David Allinson ${ }^{1}$, \\ Mohammed Quddus ${ }^{1}$ and Pete Smith ${ }^{3}$
}

1: School of Civil and Building Engineering, Loughborough University, Loughborough, LE11 3TU, UK

2: Nuffield Department of Obstetrics and Gynaecology, University of Oxford, Oxford, OX3 9DU, UK

3: Institute of Biological and Environmental Science, University of Aberdeen, Aberdeen, AB24 3UU, UK

Key words: Building energy demand, mapping, scenarios, heat, electricity, NHE, bioenergy, UKERC

Primary research article 


\begin{abstract}
Maps of energy demand from buildings in Great Britain have been created at $1 \mathrm{~km}$ square resolution. They reveal the spatial variation of demand for heat and electricity, of importance for energy distribution studies and particularly for bioenergy research given the significant distance-based restrictions on the viability of bioenergy crops.
\end{abstract}

Maps representing the spatial variation of energy demand for the year 2009 were created using publicly available sub-national gas and electricity consumption data. A new statistical model based on census data was used to increase the spatial resolution. The energy demand was split into thermal energy (the heat energy required for space heating and hot water) and electricity used for purposes other than heating (non-heating electricity or NHE), and was determined separately for the domestic and non-domestic sectors.

"Scenario factors", representing the fractional change at national level in the demand for heat and NHE, were derived from scenarios constructed by UKERC. These scenarios represent a range of pathways from the present day to 2050. The present work focused on the two cases of greatest relevance, the “Low Carbon” (LC) and “Additional Policies” (ADD) scenarios, and factors for both were derived, for the demand types described, for every five years between 2000 and 2050. Approximate future spatial energy demands can be obtained by applying the scenario factors to the base mapping data for 2009. 


\section{Introduction}

Greenhouse gas emissions from buildings represent about 39\% of the UK total (DECC, 2013a), and so provide an opportunity for the significant reductions required by UK government policy (HM Government, 2011). The majority of the emissions come from space and water heating, which accounted for nearly 37\% of all final UK energy consumption in 2010, with lighting and appliances responsible for a further 8\% (DECC, 2013b).

It is convenient when studying buildings to subdivide them into two sectors because of their differing characteristics: domestic, comprising the 26.3 million homes occupied by UK residents; and non-domestic, consisting of services (schools, offices, shops, hotels, hospitals and public buildings) and industrial (including factories, warehouses and workshops). These subdivisions are particularly relevant for the present work, because they correspond to different spatial resolutions of the local energy data on which the work is based.

Combined heat and power (CHP) provides an opportunity for emissions savings by using the waste heat from electricity generation to deliver space and water heating to buildings, typically via a district heating system. Further major emissions reductions are possible if the CHP plant is powered by biomass feedstocks which have low carbon intensity relative to fossil fuels since the carbon dioxide released during combustion is balanced by that absorbed from the atmosphere during their growth (Valentine et al., 2012). Use of bioenergy also contributes to the UK's target that 15\% of total energy be supplied by renewables by 2020 (DECC, 2011).

The viability of bioenergy crops, from both economic and emissions-reduction perspectives, has a strong dependence on the distance between where they are grown and where they are combusted in CHP plant. Because of the limited distance over which heat is transmitted in district heating systems, CHP plant is ideally sited close to the end users of the supplied heat 
energy. As a result, a knowledge of the spatial variation of heat demand arising from buildings is needed for such studies.

More generally, spatial mapping of energy demand has potential applications in several areas of energy study, including district heating (Finney et al., 2012), urban planning (Kierstead and Calderon, 2012), rural planning (Schlegel et al., 2012) and the potential for using waste heat from industry (McKenna and Norman, 2010). The importance and utility of heat mapping was demonstrated by the recent release of a UK CHP Development Map by DECC (2013c). The present work extends this concept by creating complementary electricity demand maps, thus providing a more complete picture of energy demand.

Existing energy demand data sources provide only limited spatial resolution, for example aggregate totals of several hundreds of dwellings. There is a need for finer resolution to allow detailed studies of the potential of distributed energy supply methods to be conducted. The ability to distinguish more clearly the edges of cities and different areas within them allows analysis of energy consumption at high resolution, e.g. Pereira and Assis (2013). A related need is for an extension of current energy demand maps to future years, to allow the feasibility of the proposed methods to be assessed under the different demand conditions that may exist in the future.

There is a requirement for data on two categories of energy demand: heat, in the sense of delivered thermal energy (typically less than the final energy consumption because boiler efficiencies are less than 100\%); and electricity used for purposes other than heat, referred to hereafter as non-heating electricity (NHE).

The heat demands of interest for bioenergy purposes are for space and water heating in both domestic and non-domestic sectors. Cooking use is excluded, along with all industrial uses of heat. 
The work described in this paper is in two parts. The main part is the creation of energy demand maps of Great Britain at $1 \mathrm{~km}$ resolution for heat and NHE for the base year of 2009, by disaggregating local gas and electricity supply data.

The second part is the derivation of "scenario factors" indicating how the national heat and NHE demands vary over future years according to scenarios derived by UKERC (2011, 2013b). Applying these factors to the base 2009 maps allows maps of future demand to be created. Such maps lack the subnational variation that would arise in reality; nevertheless, they provide a useful first estimate of the future energy demand landscape. 


\section{Materials and Methods}

Energy demand maps for 2009 were created by disaggregating sub-national gas and electricity consumption data for the target year using a model based on census data. In a separate process, scenario factors were derived from UKERC data for two scenarios: Low Carbon (LC) and Additional Policies (ADD).

\section{Base data for 2009}

Local gas and electricity consumption data for Britain (DECC, 2013d) were used to create base energy demand maps for 2009, the most recent year available at the time the work was carried out. The data were available for domestic and non-domestic sectors, and demand datasets for both were created. A broadly similar approach was followed in the generation of spatial maps of home-based transport energy demand by Wang C et al. (2013).

Gas consumption (excluding the cooking load) was used as a proxy for heat demand. The correction to include all heat sources (fossil fuel, electricity and others) was made in different ways for domestic and non-domestic sectors as described later. NHE demand was obtained from the electricity consumption data by subtracting the national proportion used for space and water heating.

The aim was to achieve the best spatial resolution from the data sources available, in order to obtain $1 \mathrm{~km}$ square data of the highest accuracy. Differences in the types and resolutions of available data meant that different methods were used for domestic and non-domestic sectors.

Higher spatial resolution was achievable for domestic than non-domestic data, for two reasons. First, the domestic energy data were available from the Department of Energy and Climate Change (DECC) website at the maximum-resolution lower layer super output area (LSOA) level. Second, the availability of census data based on the next higher level of 
resolution, output areas (OAs), meant that a model developed at lower spatial resolution could be used to predict energy demand at OA level, enabling a more accurate assignment of energy data to $1 \mathrm{~km}$ squares.

The non-domestic data, by contrast, were of lower resolution and lacked any equivalent to the census data modelling to improve the resolution. The half-hourly ( $\mathrm{HH})$ metered electricity data, which cover major users and comprise $71 \%$ of the non-domestic total nationally, were supplied (DECC, 2013d) at local authority (LA) level, a much lower resolution than the LSOA level of the domestic data. This was understood to be for commercial confidentiality reasons. The gas and the non-HH electricity data were provided at the middle layer super output area (MSOA) level, a higher resolution than the HH electricity data but still lower than the equivalent domestic data, again for reasons of commercial confidentiality. Figure 1 shows the relationships between the OA, LSOA, MSOA and LA elements of census geography (ONS 2013a).

In all cases, the DECC sub-national energy data required some 'cleaning'. The most important feature that required attention was the existence of 'unallocated' consumption, typically amounting to 2 - 3\% for gas. As a general principle, it was reassigned to the LSOAs or MSOAs to which it applied, in proportion to the existing consumption in those spatial units. This had the advantage of retaining overall consumption totals, a useful checking device. Another issue requiring attention was the existence of a few spatial units (MSOAs, for example) that appeared to cross LA boundaries - something that should not happen. The quantities of energy involved were negligible, and the main aim of the cleaning was to ensure data integrity. This was typically dealt with by reassigning consumption to neighbouring spatial units known to be within the LA boundaries. 
When the data had been cleaned, they were processed as described below. Since the methods used for domestic and non-domestic data differed considerably, they are described separately.

\section{Domestic data}

The gas and electricity data for the most recent year available at the time of doing the work, 2009, were obtained for England and Wales at LSOA level from the DECC website (DECC, 2013d). Scottish data are not available at this resolution but instead at intermediate geography zone (IGZ) level, roughly comparable with MSOA. The unavailability of higher-resolution energy data for Scotland meant that the development of the census model was based on data for England and Wales only. Scottish data did, however, play a role in validation as described later.

The following description of the derivation of domestic energy demand focuses on the heat data, with NHE described subsequently in terms of the small differences from this approach. Although the great majority of the gas supplied to homes is used for space and water heating, a small proportion is used for cooking. Since this is not of interest in the present work, it was excluded by subtracting the national proportion of 3\% (DECC, 2013e).

The remaining gas was assumed to be burnt in boilers in order to supply the heat to homes. Multiplying this value for each LSOA by the average UK boiler efficiency of 67\% (DECC, 2013e) gave a demand for thermal energy, usually expressed as 'heat demand' hereafter for brevity, for the LSOA. The final operation at this stage was to divide this heat demand by the number of gas meters in the LSOA, giving an average heat demand for homes supplied by gas for each LSOA in England and Wales on the assumption that all heating was by gas. 
This average heat demand was then assumed to represent the heat demand of all of the homes in the LSOA from all fuels. The process is summarized in equation (1):

$$
H_{a v, d o m}=\left[G_{d o m}\left(1-p_{\text {cooking }}\right) \eta_{\text {boiler }}\right] / N_{\text {gmeters }}
$$

where

$H_{a v, d o m}=$ average heat demand per household in the LSOA

$G_{d o m}=$ total domestic gas consumption in the LSOA

$p_{\text {cooking }}=$ national proportion of gas used for cooking $=3 \%$ (DECC, 2013e)

$\eta_{\text {boiler }}=$ national average boiler efficiency $=67 \%$ (DECC, 2013e)

$N_{\text {gmeters }}=$ number of gas meters in the LSOA.

A model was developed to predict average heat demand at OA level, in a similar way to that used by DECC (2013f) to predict local gas consumption, using the average heat demand data described above as input. This was done at both LSOA and MSOA level. Similar results for these two cases suggested that the model is fairly scale-independent, and that that it should therefore give reasonable results at the higher spatial resolution represented by OAs.

It was expected, and later confirmed, that the heat demand would be dependent on outside temperature, especially during the winter months. A spatially-resolved temperature variable was therefore constructed using mean monthly air temperatures over the period 1961-1990 at $5 \mathrm{~km}$ resolution available from the Met Office (2012). The temperatures for each $5 \mathrm{~km}$ square were averaged over the heating season (the seven months from October to April inclusive) to provide a heating season average temperature (HSAT) that related as closely as possible to the demand for space heating. 
Since the model was to apply to the whole of Great Britain, the choice of census variables was restricted to those available in both of the relevant censuses: that for England and Wales (ONS, 2013b) and that for Scotland (National Records of Scotland, 2013). Suitable census model variables were selected after testing a range of likely candidates. These are listed with their corresponding linear regression coefficients and $t$-statistics in Table 1 . The signs of the coefficients indicate that the heat demand increases with number of rooms and household size but decreases with higher average outside air temperature. This is in line with expectations in both cases. The inverse relationship between heat demand and the proportion of permanently sick household members is presumably a consequence of poverty.

Census data were drawn from the Key Statistics tables for England and Wales (ONS, 2013b). The average age was obtained from the numbers of people in different age ranges in census table KS002 by multiplying the midpoint of each age range by the frequency. The proportion working at home was obtained by dividing the number working at home by the total working, both provided in table KS015. The proportion of permanently sick was obtained by dividing the number of such persons, available in table KS009a, by the total number in the age range 16 - 74, also provided in that table. The household density was obtained by dividing the number of households, available in table KS019, by the area of the spatial unit of interest in $\mathrm{km}^{2}$. Note that "spatial unit of interest" can be OA, LSOA or MSOA in this work. The number of households was also used at the end of the process to convert heat demand per household to total heat demand for the OA, prior to assignment to $1 \mathrm{~km}$ squares. Also obtained from table KS019 were the average number of rooms per household, and average household size.

Table 1 near here 
The relevant census data and HSAT for each OA were used as input to the model. The output was an average heat demand per household for each OA in Britain, which was multiplied by the number of households in the output area to give a total heat demand $H_{\text {dom }}$ for the OA. The result can be expressed as

$$
H_{\text {dom }}=n_{\text {households }} \Sigma \alpha_{i} X_{i}
$$

where $n_{\text {households }}$ is the number of households in the OA provided by the census data and the summation is over the product of the coefficients $\alpha_{i}$ and the census variables $x_{i}$ with $x_{0}=1$.

The derivation of domestic NHE demand followed a similar method to the heat demand, with the additional feature that, after data cleaning, standard and Economy 7 electricity consumptions and meter numbers were combined. The electricity consumption associated with space heating and hot water was then removed by subtracting the national average proportion for 2008 (DECC, 2013e) of 25.4\%, which agrees well with the latest UKERC scenario data (UKERC, 2013b) and with the model of Firth et al. (2010). It is worth noting that the more recent data for 2009 do not show good agreement due to a change in calculation method (DECC, 2013e), and the older data were preferred for consistency. An efficiency of $100 \%$ was assumed for NHE demand, and so no further corrections were needed. The average NHE demand per home $N H E_{a v, d o m}$ was obtained by dividing total NHE demand for the LSOA by the total number of meters. The process is summarized in equation (3):

$$
N H E_{a v, d o m}=E_{\text {dom }}\left(1-p_{\text {heating }}\right) / N_{\text {emeters }}
$$

where

$N H E_{a v, d o m}=$ average non-heating electricity demand per household in the LSOA $E_{\text {dom }}=$ total domestic electricity consumption in the LSOA 
$p_{\text {heating }}=$ national proportion of electricity used for heating $=25.4 \%$ (DECC, 2013e)

$N_{\text {emeters }}=$ number of electricity meters in the LSOA.

A census-based model for prediction was then developed in the same way as for the heat demand data, with the only difference being the absence of a temperature variable because NHE demand was not expected to vary with outside air temperature. The variables and their corresponding linear regression coefficients and $t$-statistics are shown in Table 2 . The signs of the coefficients are not as readily explicable as for the heat demand model due to the greater variety of factors influencing electricity consumption (Wright, 2008; Coleman et al., 2012).

\section{Table 2 near here}

The output of the model was an average NHE demand per household for each OA in Britain, which was multiplied by the number of households in the output area to give a total NHE demand for the OA. The result can be expressed as

$$
N H E_{\text {dom }}=n_{\text {households }} \Sigma \beta_{i} y_{i}
$$

where $n_{\text {households }}$ is the number of households in the OA as before and the summation is over the product of the coefficients $\beta_{i}$ and the census variables $y_{i}$ with $y_{0}=1$.

Validation of the modelled domestic heat and NHE values was limited to visual inspection of the maps and comparison of the model results for Scotland with the corresponding DECC (2013d) data. In order to apply the model to Scotland it was necessary to identify the corresponding variables in the Scottish census. The equivalents to the England and Wales Key Statistics tables were used, the code names for which are identical to those for England 
and Wales except that the initial zero is omitted. So, for example, the average age was obtained from England and Wales census table KS002 and from the Scotland table KS02. A comparison of the modelled and actual total heat and NHE demands for Scotland revealed agreement within $6 \%$.

\section{Non-domestic data}

The non-domestic energy data published by DECC (2013d) are at lower spatial resolution than domestic, for commercial confidentiality reasons as described earlier. Most are provided for MSOAs or the Scottish equivalent, IGZs, but the HH-metered electricity data are provided at even lower resolution, at local authority (LA) level. The procedure below for deriving non-domestic energy demands was designed to apply to MSOA/IGZ-level data, so the first task was to assign the LA-level HH-metered electricity data to MSOAs using an approximate method. The options for doing this were limited, and amounted to assigning $\mathrm{HH}$ data in proportion to one of the following: MSOA area; non-domestic gas consumption; or non-domestic, non-HH electricity consumption.

The area of an MSOA varies inversely with population density, so use of MSOA area would assign $\mathrm{HH}$-metered electricity to the least populated areas. While this may be appropriate in some cases (because industrial areas are non-residential), it would be clearly wrong in others (e.g. mountainous areas), and for that reason was not used. Use of non-HH electricity did not seem appropriate either, for two reasons. First, it seems unlikely that the locations of large consumers using HH-metered electricity (industry and large commercial buildings) are strongly correlated with those of small non-domestic consumers such as shops and small offices and schools. And second, its use would mean that a lower level of consumption (29\% nationally) was being used to assign a much larger level (71\%), an imbalance that would magnify any errors due to the expected lack of correlation. 
These disadvantages meant that the third option was used, and the HH-metered electricity data was assigned according to the distribution of non-domestic gas consumption. Although a specific organization might not consume large amounts of both electricity and gas, it seems reasonable that there would be a correlation within a given MSOA between large users of both, in an industrial area for example.

In each MSOA, the non-HH and newly-disaggregated $\mathrm{HH}$ consumptions and meter numbers were combined into single values resulting in a list of MSOAs with non-domestic consumption data for electricity and, in most but not all cases, gas.

The requirement was to derive heat and NHE demand from these MSOA-based gas and electricity consumption data. In the absence of local information about the proportions of gas and electricity consumption used for these purposes, the only option was to assume that local consumption follows the national pattern in terms of subdivisions by end use and fuel. So the aim was to determine an expression at a national level for the dependence of heat and NHE demand on the gas and electricity totals and then to apply it to local data.

The non-domestic case differs from the domestic, described above, in three ways. First, there is no equivalent of a model using census data. Besides providing a disaggregation method, the census model assigns heat demand data derived from gas consumption to all homes in an LSOA, no matter what their heating method. So for the non-domestic sector it was necessary to determine the heat demand from both electricity and gas consumption. Second, there is a greater range of end-uses of energy in the industrial sub-sector. Third, in both industrial and services sub-sectors there are four fuels that need to be taken into account: electricity, natural gas, oil and solid fuel.

If CHP (and other power generation) is excluded, the fossil fuels (natural gas, oil and solid fuel) can only supply heat, while electricity can supply heat as well as power. So, following 
the simple basis adopted for the domestic sector, the main subdivision for energy use was between heat demand and non-heating electricity (NHE) demand, where NHE is used for all non-heat purposes and no heat purposes.

Unlike the domestic case, space and water heating represent a minority of the industrial uses of heat. So heat demand was split into a range of end-uses, allowing the particular area of interest (heat demand that can be satisfied by biomass) to be separated out while ensuring the other categories were visible and accounted for.

Data on annual industrial and services energy end-use were taken from Tables 4.7 and 5.6 of the industrial and services energy consumption data (DECC, 2013e). The end-uses were each assigned to a demand type (NHE or heat) and to an end-use category: either 'All' if the type was NHE or one of 'Heating and hot water'(HHW), 'Industrial process', 'Catering' or 'Other' if the type was heat. The categorization is shown in Table 3.

Note that services 'Other' has been classed as NHE but industrial 'Other' has been categorized as heat. This has been done on the basis of the fuel breakdown (services is mainly electricity while industry is mainly fossil) and differs from DECC's own analysis (DECC, 2013g) which excludes industrial 'Other' from the total heat demand.

Table 3 near here

Assigning energy consumption values from DECC’s Tables 4.7 and Table 5.6 to the enduse categories in Table 3 gives the results shown in Table 4. Note the minimal consumption of fossil fuels (135 ktoe of natural gas and 10 ktoe of oil, forming 1.4\% of the total) attributed to NHE. 
This table provides a framework for deriving two relationships: one between the nondomestic heat demand responsible for the Heating \& HW load and the electricity and gas energy consumption data; and one between the non-domestic NHE demand and the electricity consumption data. An advantage of the categorization adopted is that account can be taken of the different efficiencies of fuels and end uses.

\section{Table 4 near here}

Expressions for the non-domestic heat and NHE demands in terms of the MSOA gas and electricity consumptions can be written down very straightforwardly by assuming that all proportions of fuels and end uses are as in Table 4, that electricity consumption is $100 \%$ efficient and that the average boiler efficiency for all fossil fuels is the same as for domestic gas: $67 \%$. The expressions are

$$
\begin{gathered}
H_{\text {non-dom }}=a E_{\text {non-dom }}+\eta_{f} b G_{\text {non-dom }} \\
N H E_{\text {non-dom }}=c E_{\text {non-dom }}
\end{gathered}
$$

where

$H_{\text {non-dom }}=$ total non-domestic heat demand for space heating and hot water for the MSOA $N H E_{n o n-d o m}=$ total non-domestic NHE demand for the MSOA

$E_{\text {non-dom }}=$ total non-domestic electricity consumption for the MSOA

$G_{n o n-d o m}=$ total non-domestic gas consumption for the MSOA

$a=2,142 / 16,757=0.1278$

$b=(7,445+1,311+139) / 16,864=0.5275$

$c=10,024 / 16,757=0.5982$

$\eta_{f}=0.67$. 
Equations (5) and (6) were used to derive non-domestic heat and NHE demand from the MSOA-based energy consumption data. Area-weighted averaging was then used to assign the values to $1 \mathrm{~km}$ squares.

\section{Scenario factors}

Future demand was determined using UKERC scenarios to ensure consistency with other UKERC projects and because they contain appropriate data at the required level of detail. In particular, they provide detailed numerical data on projected energy use in the relevant sectors. It should be noted, however, that the UKERC scenarios apply at national level only, and no subnational (e.g. regional) variations are represented. This means that it is possible to derive simple multipliers, referred to as "scenario factors", for representing future variations in energy demand, but also means that maps produced using them are simple multiples of the base 2009 maps.

The aim was to derive a set of scenario factors for the years to 2050 for each of four demand types (domestic or non-domestic, and heat or NHE) and scenario of interest. The energy demand for a given $1 \mathrm{~km}$ square for a future year, demand type and scenario is then given by multiplying the value in the same square in the base 2009 data by the relevant scenario factor.

The scenarios created by UKERC (2011, 2013b) consist of a set of detailed quantitative descriptions of routes between the present day and 2050. The variations result from different assumptions about how energy consumption in different sectors will respond to policy and regulation.

The 'refreshed' scenario set (UKERC, 2013b) comprises 16 scenarios in all, covering a range of possible futures and considering important variations. Four scenarios form the core set: Reference (REF), Low Carbon (LC), Policy Gap (GAP) and Additional Policies (ADD). 
Each can have four variants: the Standard Case, Resilience, Decoupled Gas Price and combined Resilience and Decoupled Gas Price. Attention was focused on the ADD and LC scenarios because they display significant differences, especially with regard to bioenergy, and so represent a reasonable range of variation.

The scenarios begin in 2000, with data provided for every five years up to 2050. It was assumed for present purposes that the 2010 scenarios represent the UK as described in the 2009 maps described above. This is not strictly true, since there is a one-year difference and in addition there is already divergence in the scenarios from their common start in 2000. But the differences are small, and this approach does mean that a common baseline could be obtained for the base year with all variations occurring with respect to that year.

Figure 2 near here

The scenarios are presented in terms of final energy. The LC scenario is shown in Fig. 2, demonstrating a drastic reduction in gas consumption over the period of interest so that it satisfies none of the demand by 2050, the only remaining contributions being heat pumps (36\%), solid fuel (31\%) and solar (28\%), with small amounts of electricity (4\%) and district heating (1\%). Note that although heat pumps are assumed to be electrically powered, they are considered separately from electricity because of the different conversion efficiency.

The projection of a strong overall reduction in supplied domestic heating energy shown in Fig. 2 appears unrealistic on the face of it. However, the situation is explained when the data are converted into delivered thermal energy for use in the present work. In order to do this, assumptions are necessary about the conversion efficiencies of the various energy sources. 
For simplicity, it was assumed that all efficiencies are constant over time. For the same reason, the same efficiencies were used for a given fuel whether used in a domestic, services or industrial context. In keeping with the overall approach in the present work, approximate efficiencies representative of the broad range of appliances were used. The values used are shown in Table 5.

\section{Table 5 near here}

A higher efficiency was used for conventional gas than was used for deriving the base 2009 demands, to take account of replacement of older, low-efficiency appliances over the period of interest. The value of 0.9 for condensing boilers is a little lower than manufacturers' figures to take account of real-world operating conditions. The efficiency of electrical resistance heating was taken as the conventional value of 1 , while the coefficient of performance (COP) of heat pumps was set mid-way between the ranges for air-source and ground-source types quoted in UKERC (2011). Coal and coke, solid/wood fuel and oil were given values currently achievable in industrial systems (ETSAP, 2010). District heating, steam and solar were assumed to be delivered as thermal energy and so not require conversion.

The demand for the delivered thermal energy from each fuel was obtained by multiplying its UKERC final energy demand by the corresponding conversion efficiency in Table 5 . The result for the domestic heat demand in the LC scenario is shown in Fig. 3, and represents the delivered thermal energy equivalent of Fig. 2. The overall result over the period is a reduction in domestic demand for thermal energy of $22 \%$, implying a significant but feasible improvement in the average energy efficiency of the housing stock which could be achieved 
by an extensive insulation programme, for example. It is clear that the efficiency with the greatest influence on the present work is the COP of heat pumps.

Figure 3 near here

\section{Domestic scenario factors}

Calculation of scenario factors for the domestic sector was straightforward. For heat demand, final energy demand for each category (conventional and condensing gas boilers, electricity for heat, electricity for heat pumps, coal, oil, solid/wood fuel, district heating and solar) was multiplied by the corresponding conversion efficiency in Table 5 and the results summed to give total thermal energy demand. Scenario factors were obtained by dividing this value for each year (2000 to 2050 in steps of five years) by the value for 2010, the closest to our base year of 2009.

The NHE demand was determined by subtracting the electricity used for heating and for heat pumps from the total domestic electricity consumption. The NHE demand for each year of interest was then divided by the 2010 value, resulting in a set of scenario factors.

Non-domestic scenario factors

Calculation of non-domestic scenario factors required the determination of thermal energy and NHE demands from the UKERC scenario data. The service sub-sector data are presented in a similar form to the domestic data and the same method was used. The industrial energy consumption data, however, are presented in less detail and do not include the categories of space heating or NHE. Approximate calculation methods were therefore necessary to obtain 
industrial thermal energy and NHE demands which could be added to the service values to allow scenario factors to be determined.

An estimate of the total delivered thermal energy for industrial space heating $E_{t h, s p}$ in each year of interest (2000 to 2050 in steps of five years) was derived as follows. The required value is the sum of the delivered thermal energies for the fuels of interest,

$$
E_{t h, s p}=\sum E_{t h, s p, i}
$$

where each value of the subscript $i$ corresponds to a different fuel. The final and delivered thermal energies are related by

$$
E_{t h, s p, i}=\eta_{i} E_{f i, s p, i}
$$

where $E_{f i, s p, i}$ is the final space heating energy delivered by fuel $i$, and $\eta_{i}$ is the conversion efficiency in Table 5. An approximate value for the delivered final space heating $E_{f i s p, i}$ is obtained by assuming that

- the proportion $s$ of total final industrial energy used for space heating is constant over time and equal to the value in 2009;

- the proportion of this consumption attributable to each fuel is equal to that for the low-temperature industrial heat consumption in the UKERC scenarios;

- the penetration of heat pumps in the industrial sub-sector matches that for services.

These assumptions allow an expression to be written down for the final space heating demand for fuel $i$,

$$
E_{f i, s p, i}=p_{i}\left(s E_{t o t}\right)
$$


where $p_{i}$ is the proportion of low-temperature heat provided by fuel $i, s$ is the proportion of the total final industrial energy used for space heating in 2009 and $E_{\text {tot }}$ is the total industrial final energy consumption in the year of interest. Heat pumps are not distinguished from electricity for resistance heating in the UKERC low-temperature heat data so the electricity fraction was subdivided into electricity for resistance heating and electricity for heat pumps using the same proportions as the service sub-sector.

Combining (7), (8) and (9) gives the final equation for thermal energy demand for industrial space heating

$$
E_{\text {th,sp }}=s E_{\text {tot }} \sum \eta_{i} p_{i}
$$

where the $\eta_{i}$ are obtained from Table $5, E_{\text {tot }}$ and the $p_{i}$ are derived from the UKERC scenarios and $s$ was obtained by dividing the total industrial final energy demand for space heating by the total industrial final energy demand, both taken from Table 4.7 of the DECC energy consumption data for 2009 (DECC, 2013e), with a resulting value of 10.2\%.

The non-domestic scenario factors for thermal energy demand were then obtained by summing the service and industrial sub-sectoral contributions for each year and dividing by the values for 2010 .

Similar considerations were used for deriving the industrial NHE demand. In this case it was assumed that the proportion of the total industrial electricity demand used for NHE was constant and equal to the value for 2009. The proportion of electricity demand represented by NHE was taken to be the sum of the consumptions for motors, compressed air, lighting and refrigeration divided by the total industrial electricity consumption, with a value of $51.1 \%$. The industrial NHE for each scenario year of interest was then obtained by multiplying this proportion by the total industrial electricity demand appearing in the UKERC scenarios. 
Maps for future years were produced by multiplying the base 2009 maps by the relevant scenario factor. This is clearly an approximate procedure. It takes no account of local variation of any type so that, for example, changes in the location of settlements (e.g. new towns) or industrial facilities are not considered. In essence, the underlying dynamics that would have led to spatial variations have been ignored in order to obtain approximate energy demand maps for future years. The approach has the advantage that it is straightforward to modify the energy demand maps for future years if, as has already happened (UKERC, 2013b), the scenarios are updated. 


\section{Results}

\section{Base 2009 data}

The four base maps for 2009 energy demand are presented in Figs. 4 to 7. Figures 4 and 5 contain domestic heat and NHE demand respectively, and Figs. 6 and 7 the corresponding non-domestic data. The reduced resolution of the non-domestic maps due to restrictions on data availability referred to earlier is clearly visible. A clear feature of all maps is the concentration of demand in urban areas, to the extent that towns and cities can be readily identified.

The full set of 2009 data created as part of the DS4DS project (DS4DS, 2013) has been lodged with the UKERC Energy Centre (UKERC, 2013a) and is available for general use.

\section{Scenario factors}

The results for the ADD and LC scenarios are shown in Tables 6 and 7 respectively. Since the scenario factors are ratios of annual energy demands (for the year of interest to that of 2010), they are dimensionless with values for 2010 equal to unity in all cases.

Tables 6 and 7 near here

Although there are some detailed variations, the broad sweep of the scenario factors is similar: domestic heat demand falls by moderate amounts (10 to $22 \%$ ) over the period to 2050 while all other categories rise, with non-domestic heat increasing more sharply than NHE. 


\section{Maps for future demand}

Application of the scenario factors to the base maps shown in Figs. 4 to 7 provides approximate maps of future demands. Since the factors are at national level, they multiply all energy demand values in a given map equally, with the result that the base case map represents future demands when changes are made in the figure legend. This is achieved by multiplying each range limit by the scenario factor. For example, the non-domestic heat demand in 2050 according to the ADD scenario is represented by the map in Fig. 6 with the range boundaries in the legend multiplied by 1.38. The lowest range is then 'Below 0.0138', followed by 0.0138 to $0.0414,0.0414$ to 0.138 and so on. The number of entries in each range (e.g. $n=46,190)$ is unchanged.

Figures 4 to 7 near here 


\section{Discussion}

\section{Implications}

The main outcome of the present work is a set of maps of spatially disaggregated energy demand for 2009 and a simple method for applying scenarios to such data to provide spatial maps of energy demand for future years. The maps have the expected form: high energy demand, for both heat and NHE, in urban areas and the converse in rural areas. The scenario factor results can be concisely presented, as shown in Tables 6 and 7, and in themselves provide useful insights into the energy futures enshrined in the scenarios. The key feature of both LC and ADD scenario factors is the fall in domestic heat demand between the present day and 2050 by 10 to 22\%. Since there will be a continuing desire into the future for comfortable homes (and indeed there will be more of them), this must imply improved energy efficiency. It is notable that this applies to the domestic sector only; there is no corresponding improvement in the non-domestic sector. The scenario descriptions (UKERC, 2013b) suggest that the main driver for improvement beyond existing policies is the inclusion of the Green Deal (DECC, 2013h). The contrast between Figs 2 and 3 demonstrates the strong dependence of domestic energy demand reduction in these scenarios on a widespread take-up of heat pumps with high coefficients of performance.

\section{Reliability of the results}

Assumptions and approximations were used at various points in the derivation of the results. These were minimal in the determination of the base 2009 energy maps for the domestic sector, because the DECC energy data were available at high resolution and the census model used to improve the resolution further was demonstrated to be scale-independent. 
The lower resolution of the non-domestic DECC energy data meant that several assumptions were needed to allow derivation of energy demands at $1 \mathrm{~km}$ square resolution. These mainly took the form of assuming that the distribution of local energy demand among different sources follows national values.

One exception was the method use to assign LA-level HH metered electricity data to MSOAs, by assuming the distribution follows the pattern of non-domestic gas. While not unreasonable, this is clearly an approximate procedure, and the reliability of the results should be seen in that light.

Turning to the scenario factors, approximations can be identified at two levels. Most importantly, it was necessary to make assumptions about the conversion efficiencies of the various technologies to allow the thermal energy demands to be deduced from the final energy demands. In some ways this seems surprising, since in principle the thermal demands must be present in the UKERC models to allow the final energy demands to be determined. But discussion with those involved in the work (Keppo, 2013) revealed that the thermal demands are too deeply embedded in the models to allow their values to be extracted.

Most of the conversion efficiencies are quite close to unity and will be reasonably reliable. The exception is the value for heat pumps. A value was chosen to reflect equal numbers of ground-source and air-source heat pumps, using the COP values of the middle of the ranges quoted by UKERC (2011). The contrast between Figs. 2 and 3 shows the importance of this COP in the calculations and therefore how sensitive they are to a change in its value. It also shows how strongly the success of the LC scenario in particular depends on this level of heat pump performance being delivered.

The approximations in the derivation of the scenario factors at the second level mirror those used for the base maps: domestic data can be derived relatively straightforwardly while non- 
domestic require the application of national distributions of energy demand. This is in the industrial sub-sector only, however, with the service sub-sector behaving like domestic.

This application of national proportions of energy use to local data, in the derivations of both the base 2009 data and the scenario factors, amounts to an assumption of no regional variation, which is clearly only a rough approximation. The reliability of the results would be improved by accurate local data, but in their absence it is the best that can be done. The inaccuracy is unlikely to cause serious difficulties, for two reasons. First, national averages will usually give a reasonably representative picture. Second, the necessarily speculative nature of scenarios for several decades hence means that there is less need for high accuracy in the input data. It is worth emphasizing that many details of future changes in the energy system are captured by the UKERC scenarios, and these are taken fully into account in the present work.

Other approximations include the derivation of scenario factors from UK data while the DECC data to which they are applied are for Great Britain - that is, they exclude Northern Ireland. Given the other contributions to unreliability discussed above, this is not considered to be a serious issue. 


\section{Nomenclature}

ADD 'Additional Policies’ UKERC scenario

CHP Combined heat and power

COP Coefficient of performance

DECC Department of Energy and Climate Change

HH Half-hourly

HHW Heating and hot water

HSAT Heating season average temperature

IGZ Intermediate Geography Zone: Scottish spatial unit roughly comparable to MSOA

LA Local authority

LC 'Low Carbon’ UKERC scenario

LSOA Lower layer super output area

MSOA Middle layer super output area

NHE Non-heating electricity

OA Output area

UKERC United Kingdom Energy Research Centre 


\section{Acknowledgments}

The Disaggregated Scenarios for Demand Studies (DS4DS) project (DS4DS, 2013) was funded between July 2011 and June 2012 by the United Kingdom Energy Research Centre (UKERC) under the ' $3{ }^{\text {rd }}$ round research call'. For more information see www.ds4ds.org and www.ukerc.ac.uk. Two of the authors (SCT and SKF) acknowledge support by the Engineering and Physical Sciences Research Council (EPSRC) under their Sustainable Urban Environment programme (grant EP/I002154/1) to SECURE: Self Conserving Urban Environments, https://www.secure-project.org/. SECURE is a consortium of four UK universities: Newcastle University, the University of Sheffield, the University of Exeter and Loughborough University. PS is a Royal Society-Wolfson Research Merit Award holder. 


\section{References}

Coleman M, Brown N, Wright A, Firth SK (2012). Information, communication and entertainment appliance use-Insights from a UK household study. Energy and Buildings 54, 61-72.

DECC (2011). Department of Energy and Climate Change. UK Renewable Energy Roadmap, July 2011. Available at:

http://www.decc.gov.uk/assets/decc/11/meeting-energy-demand/renewable-energy/2167uk-renewable-energy-roadmap.pdf (Accessed 29 Nov 2013).

DECC (2013a). Department of Energy and Climate Change. 2011 final UK figures: statistical release. Available at:

https://www.gov.uk/government/publications/final-uk-emissions-estimates (Accessed 29 Nov 2013)

DECC (2013b). Department of Energy and Climate Change. Energy consumption in the UK: overall tables. Available

at: http://www.decc.gov.uk/assets/decc/Statistics/publications/ecuk/266-ecuk-overall2010.xls (Accessed 29 Nov 2013).

DECC (2013c). Department of Energy and Climate Change. UK CHP Development Map. Available at: http://chp.decc.gov.uk/developmentmap/index.php (Accessed 29 Nov 2013).

DECC (2013d). Department of Energy and Climate Change. Sub-National Energy Consumption Statistics. Available at: http://www.decc.gov.uk/en/content/cms/statistics/energy_stats/regional/regional.aspx (A ccessed 29 Nov 2013) 
DECC (2013e). Department of Energy and Climate Change. Energy consumption statistics website http://www.decc.gov.uk/en/content/cms/statistics/publications/ecuk/ecuk.aspx (Accessed 29 Nov 2013)

DECC (2013f). Department of Energy and Climate Change. Identifying local areas with higher than expected domestic gas use. Available at: http://www.decc.gov.uk/assets/decc/11/stats/publications/energy-trends/articles/4785las-higher-expected-dom-gas-use-article.pdf (Accessed 19 Dec 2012)

DECC (2013g). Department of Energy and Climate Change. Energy consumption in the United Kingdom: 2012. Industrial energy consumption in the UK since 1970. Available at: http://www.decc.gov.uk/assets/decc/11/stats/publications/energy-consumption/2327factsheet-industrial-energy-consumption.pdf (Accessed 29 Nov 2013)

DECC (2013h). Department of Energy and Climate Change. Final Stage Impact Assessment for the Green Deal and Energy Company Obligation. Available at: http://www.decc.gov.uk/assets/decc/11/consultation/green-deal/5533-final-stage-impactassessment-for-the-green-deal-a.pdf (Accessed 29 Nov 2013)

DS4DS (2013). Project website http://www.ds4ds.org (Accessed 29 Nov 2013) ETSAP (2010). Industrial combustion boilers. ETSAP Technology Brief I01, Energy Technology Systems Analysis Programme, International Energy Agency. Available at: http://www.iea-etsap.org/web/e-techds/pdf/i01-ind_boilers-gs-ad-gct1.pdf (Accessed 29 Nov 2013)

Finney KN, Sharifi VN, Swithenbank J, Nolan A, White S, Ogden S (2012). Developments to an existing city-wide district energy network - Part I: Identification of potential expansions using heat mapping. Energy Conversion and Management 62, 165-175. 
Firth SK, Lomas KJ, Wright AJ (2010). Targeting household energy-efficiency measures using sensitivity analysis. Building Research and Information 38, 25-41.

HM Government (2011). The Carbon Plan: Delivering our low carbon future, December 2011. Available at: http://www.decc.gov.uk/assets/decc/11/tackling-climate-change/carbonplan/3702-the-carbon-plan-delivering-our-low-carbon-future.pdf (Accessed 29 Nov 2013) Keppo I (2013). Private communication.

Kierstead J, Calderon C (2012). Capturing spatial effects, technology interactions, and uncertainty in urban energy and carbon models: Retrofitting newcastle as a case-study. Energy Policy 46, 253-267.

McKenna RC, Norman JB (2010). Spatial modelling of industrial heat loads and recovery potentials in the UK. Energy Policy 38, 5878-5891.

Met Office (2012). $5 \mathrm{~km}$ long term average air temperature website http://data.gov.uk/dataset/ukcp09-5km-gridded-data-long-term-average-data-meanair-temperature (Accessed 29 Nov 2013)

National Records of Scotland (2013). Census data website http://www.scotlandscensus.gov.uk/en/ (accessed 29 Nov 2013) ONS (2013a). Office for National Statistics, 2011 Census: Digitised Boundary Data (England and Wales) [computer file]. UK Data Service Census Support. Downloaded from: http://edina.ac.uk/census (Accessed 29 Nov 2013)

ONS (2013b). Office for National Statistics. Census 2001 Key Statistics, Local Authorities in England and Wales. Available at: http://www.ons.gov.uk/ons/rel/census/census-2001-key-

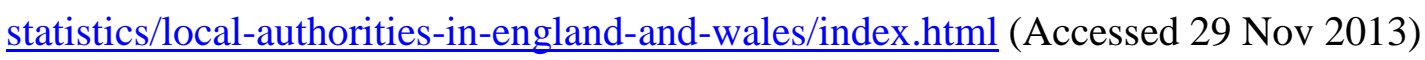


Pereira IM, Assis ES (2013). Urban energy consumption mapping for energy management. Energy Policy 59, 257-269.

Schlegel M, Trutnevyte E, Scholz, RW (2012). Patterns of residential heat demand in rural Switzerland. Building Research \& Information 40, 140-153.

UKERC (2011). Energy 2050 - Making the Transition to a Secure Low-Carbon Energy System, Eds. Jim Skea, Paul Ekins, Mark Winskel. Earthscan, 2011.

UKERC (2013a). Energy Data Centre. http://ukedc.rl.ac.uk/ (Accessed 29 Nov 2013)

UKERC (2013b). The UK energy system in 2050: Comparing Low-Carbon, Resilient Scenarios. Available at: http://www.ukerc.ac.uk/support/tikidownload_file.php?fileId=2976 (Accessed 29 Nov 2013)

Valentine J, Clifton-Brown J, Hastings A, Robson P, Allison G, Smith P (2012). Food vs. fuel: the use of land for lignocellulosic 'next generation' energy crops that minimize competition with primary food production. Global Change Biology - Bioenergy 4, 1-19.

Wang C, Firth S, Taylor S, Quddus M (2013). Spatially disaggregated domestic road transport energy demand in Great Britain. Paper presented at the Transportation Research Board 92 ${ }^{\text {nd }}$ Annual Meeting, Washington DC, USA, 13-17 January 2013.

Wang S, Hastings A, Wang SC, Sunnenberg G, Tallis MJ, Casella E, Taylor S, Wang C, Alexander P, Cisowska I, Lovett A, Taylor G, Firth S, Finch J, Moran D, Morison J, Smith P (2013). The potential for bioenergy crops to contribute to meeting GB heat and electricity demands. Global Change Biology Bioenergy (submitted).

Wright A (2008). What is the relationship between built form and energy use in dwellings? Energy Policy 36, 4544-4547. 
Table 1. Census variables and model constants for the heat demand model

\begin{tabular}{|c|c|c|c|c|c|c|}
\hline & & \multicolumn{2}{|c|}{ LSOA } & \multicolumn{2}{|c|}{ MSOA } & \multirow{2}{*}{$\begin{array}{c}\text { Average } \\
\text { Coefficients } \\
\alpha_{i} \\
\end{array}$} \\
\hline $\bar{i}$ & $\begin{array}{l}\text { Census and other } \\
\text { variables } x_{i}\end{array}$ & Coefficient & t-statistic & Coefficient & t-statistic & \\
\hline 1 & Average age & 0.0083 & 35.89 & 0.0080 & 14.47 & 0.00815 \\
\hline 2 & $\begin{array}{l}\text { Proportion working } \\
\text { from home }\end{array}$ & 1.2122 & 42.74 & 1.3009 & 21.97 & 1.25655 \\
\hline 3 & $\begin{array}{l}\text { Proportion of } \\
\text { permanently sick }\end{array}$ & -0.6200 & -17.13 & -0.5477 & -7.32 & -0.58385 \\
\hline 4 & $\begin{array}{l}\text { log(household } \\
\text { density) }\end{array}$ & 0.0323 & 43.23 & 0.0494 & 32.78 & 0.04085 \\
\hline 5 & $\begin{array}{l}\text { Average number of } \\
\text { rooms per household }\end{array}$ & 0.1690 & 95.20 & 0.1737 & 43.59 & 0.17135 \\
\hline 6 & $\begin{array}{l}\text { Average household } \\
\text { size }\end{array}$ & 0.0922 & 22.55 & 0.1122 & 12.14 & 0.10220 \\
\hline 7 & $\begin{array}{l}\text { HSAT (heating } \\
\text { season average } \\
\text { temperature) }\end{array}$ & -0.0599 & -48.65 & -0.0660 & -30.03 & -0.06295 \\
\hline 0 & 1 (constant term) & 7.8186 & 435.27 & 7.6907 & 194.31 & 7.75465 \\
\hline \multicolumn{2}{|c|}{$\begin{array}{l}\text { Number of "regions of } \\
\text { interest" }\end{array}$} & \multicolumn{2}{|c|}{33745} & \multicolumn{2}{|c|}{7155} & \\
\hline \multicolumn{2}{|c|}{$r^{2}$} & \multicolumn{2}{|c|}{0.6027} & \multicolumn{2}{|c|}{0.5999} & \\
\hline
\end{tabular}


Table 2. Census variables and model constants for the NHE demand model

\begin{tabular}{|c|c|c|c|c|c|c|}
\hline & & \multicolumn{2}{|c|}{ LSOA } & \multicolumn{2}{|c|}{ MSOA } & \multirow{2}{*}{$\begin{array}{c}\text { Average } \\
\text { Coefficients } \\
\beta_{i} \\
\end{array}$} \\
\hline $\boldsymbol{i}$ & $\begin{array}{l}\text { Census and other } \\
\text { variables } y_{i}\end{array}$ & Coefficient & t-statistic & Coefficient & t-statistic & \\
\hline 1 & Average age & -0.0034 & -17.18 & -0.0051 & -11.50 & -0.00425 \\
\hline 2 & $\begin{array}{l}\text { Proportion working } \\
\text { from home }\end{array}$ & 1.4375 & 63.37 & 1.7320 & 38.71 & 1.58475 \\
\hline 3 & $\begin{array}{l}\text { Proportion of } \\
\text { permanently sick }\end{array}$ & -1.6371 & -53.60 & -1.9520 & -33.16 & -1.79455 \\
\hline 4 & $\begin{array}{l}\text { log(household } \\
\text { density) }\end{array}$ & -0.0266 & -43.29 & -0.0200 & -17.19 & -0.02330 \\
\hline 5 & $\begin{array}{l}\text { Average number of } \\
\text { rooms per household }\end{array}$ & 0.0839 & 55.75 & 0.0786 & 24.91 & 0.08125 \\
\hline 6 & $\begin{array}{l}\text { Average household } \\
\text { size }\end{array}$ & -0.0097 & -2.74 & -0.0228 & -3.08 & -0.01625 \\
\hline 0 & 1 (constant term) & 8.0354 & 574.67 & 8.1018 & 270.22 & 8.06860 \\
\hline \multicolumn{2}{|c|}{$\begin{array}{l}\text { Number of "regions of } \\
\text { interest" }\end{array}$} & \multicolumn{2}{|c|}{34379} & \multicolumn{2}{|c|}{7193} & \\
\hline \multicolumn{2}{|c|}{$r^{2}$} & \multicolumn{2}{|c|}{0.6301} & \multicolumn{2}{|c|}{0.7145} & \\
\hline
\end{tabular}


Table 3. Assignment of end-uses of non-domestic energy

\begin{tabular}{|l|l|l|l|}
\hline Sector & End use & $\begin{array}{l}\text { Demand } \\
\text { type }\end{array}$ & End-use category \\
\hline Industry & Motors & NHE & All \\
\hline Industry & Compressed Air & NHE & All \\
\hline Industry & Lighting & NHE & All \\
\hline Industry & Refrigeration & NHE & All \\
\hline Industry & High temperature process & Heat & Industrial process \\
\hline Industry & Low Temperature Process & Heat & Industrial process \\
\hline Industry & Drying / Separation & Heat & Industrial process \\
\hline Industry & Space Heating & Heat & Heating \& HW \\
\hline Industry & Other & Heat & Other \\
\hline Services & Computing & NHE & All \\
\hline Services & Lighting & NHE & All \\
\hline Services & Cooling and Ventilation & NHE & All \\
\hline Services & Other & NHE & All \\
\hline Services & Catering & Heat & Catering \\
\hline Services & Hot Water & Heat & Heating \& HW \\
\hline Services & Heating & Heat & Heating \& HW \\
\hline
\end{tabular}


Table 4. Non-domestic energy consumption for 2009 in thousands of tonnes of oil equivalent (ktoe) for the chosen end-use categories

\begin{tabular}{|l|l|r|r|r|r|r|}
\hline $\begin{array}{c}\text { Demand } \\
\text { Type }\end{array}$ & End-use category & Electricity & $\begin{array}{c}\text { Natural } \\
\text { Gas }\end{array}$ & Oil & Solid Fuel & Total \\
\hline \multirow{4}{*}{ Heat } & Heating \& HW & 2,142 & 7,445 & 1,311 & 139 & $\mathbf{1 1 , 0 3 7}$ \\
\cline { 2 - 7 } & Industrial process & 3,067 & 7,533 & 1,750 & 1,272 & $\mathbf{1 3 , 6 2 2}$ \\
\cline { 2 - 7 } & Catering & 1,095 & 572 & 34 & - & $\mathbf{1 , 7 0 2}$ \\
\cline { 2 - 7 } & Other & 427 & 1,180 & 294 & 146 & $\mathbf{2 , 0 4 7}$ \\
\hline NHE & All & 10,024 & 135 & 10 & - & $\mathbf{1 0 , 1 6 9}$ \\
\hline Total & & $\mathbf{1 6 , 7 5 7}$ & $\mathbf{1 6 , 8 6 4}$ & $\mathbf{3 , 3 9 8}$ & $\mathbf{1 , 5 5 7}$ & $\mathbf{3 8 , 5 7 6}$ \\
\hline
\end{tabular}


Table 5. Heat conversion efficiencies

\begin{tabular}{|l|c|}
\hline \multicolumn{1}{|c|}{ Fuel } & $\begin{array}{c}\text { Heat } \\
\text { conversion } \\
\text { efficiency }\end{array}$ \\
\hline Gas (conventional boilers) & 0.75 \\
\hline Gas (condensing boilers) & 0.9 \\
\hline Electricity & 1 \\
\hline Heat pumps & 3.7 \\
\hline Coal and coke & 0.85 \\
\hline Oil & 0.8 \\
\hline Solid/wood fuel & 0.7 \\
\hline District heating and steam & 1 \\
\hline Solar & 1 \\
\hline
\end{tabular}


Table 6. ADD scenario factors

\begin{tabular}{|l|l|l|l|l|l|l|l|l|l|l|l|l|}
\hline & & $\mathbf{2 0 0 0}$ & $\mathbf{2 0 0 5}$ & $\mathbf{2 0 1 0}$ & $\mathbf{2 0 1 5}$ & $\mathbf{2 0 2 0}$ & $\mathbf{2 0 2 5}$ & $\mathbf{2 0 3 0}$ & $\mathbf{2 0 3 5}$ & $\mathbf{2 0 4 0}$ & $\mathbf{2 0 4 5}$ & $\mathbf{2 0 5 0}$ \\
\hline \multirow{3}{*}{ Heat } & Dom & 1.05 & 1.01 & 1.00 & 1.00 & 0.98 & 0.97 & 0.93 & 0.90 & 0.90 & 0.91 & 0.90 \\
\cline { 2 - 13 } & Non-dom & 1.07 & 1.05 & 1.00 & 1.03 & 1.10 & 1.13 & 1.13 & 1.19 & 1.30 & 1.29 & 1.38 \\
\hline \multirow{2}{*}{ NHE } & Dom & 0.86 & 0.95 & 1.00 & 1.03 & 1.02 & 1.09 & 1.10 & 1.07 & 1.05 & 1.09 & 1.15 \\
\cline { 2 - 11 } & Non-dom & 1.01 & 1.02 & 1.00 & 1.02 & 1.04 & 1.06 & 1.10 & 1.13 & 1.16 & 1.22 & 1.28 \\
\hline
\end{tabular}


Table 7. LC scenario factors

\begin{tabular}{|l|l|l|l|l|l|l|l|l|l|l|l|l|}
\hline & & $\mathbf{2 0 0 0}$ & $\mathbf{2 0 0 5}$ & $\mathbf{2 0 1 0}$ & $\mathbf{2 0 1 5}$ & $\mathbf{2 0 2 0}$ & $\mathbf{2 0 2 5}$ & $\mathbf{2 0 3 0}$ & $\mathbf{2 0 3 5}$ & $\mathbf{2 0 4 0}$ & $\mathbf{2 0 4 5}$ & $\mathbf{2 0 5 0}$ \\
\hline \multirow{2}{*}{ Heat } & Dom & 1.04 & 1.02 & 1.00 & 0.96 & 0.91 & 0.91 & 0.94 & 0.86 & 0.88 & 0.82 & 0.78 \\
\cline { 2 - 12 } & Non-dom & 1.06 & 1.04 & 1.00 & 0.99 & 1.06 & 1.05 & 1.04 & 1.14 & 1.17 & 1.19 & 1.24 \\
\hline \multirow{2}{*}{ NHE } & Dom & 0.90 & 0.97 & 1.00 & 1.01 & 0.93 & 1.03 & 1.05 & 1.03 & 1.06 & 1.05 & 1.06 \\
\cline { 2 - 11 } & Non-dom & 1.01 & 1.00 & 1.00 & 0.98 & 0.97 & 0.99 & 1.04 & 1.08 & 1.10 & 1.14 & 1.18 \\
\hline
\end{tabular}




\section{Figure legends}

Figure 1. UK Census geography (ONS, 2013a)

Figure 2. Final energy used for domestic heating in the LC scenario (UKERC, 2013b)

Figure 3. Domestic thermal energy demand in the LC scenario, derived from UKERC (2013b)

Figure 4. Domestic thermal energy demand for space and water heating for Great Britain in 2009

Figure 5. Domestic non-heating electricity (NHE) demand for Great Britain in 2009

Figure 6. Non-domestic thermal energy demand for space and water heating for Great Britain in 2009

Figure 7. Non-domestic non-heating electricity (NHE) demand for Great Britain in 2009 


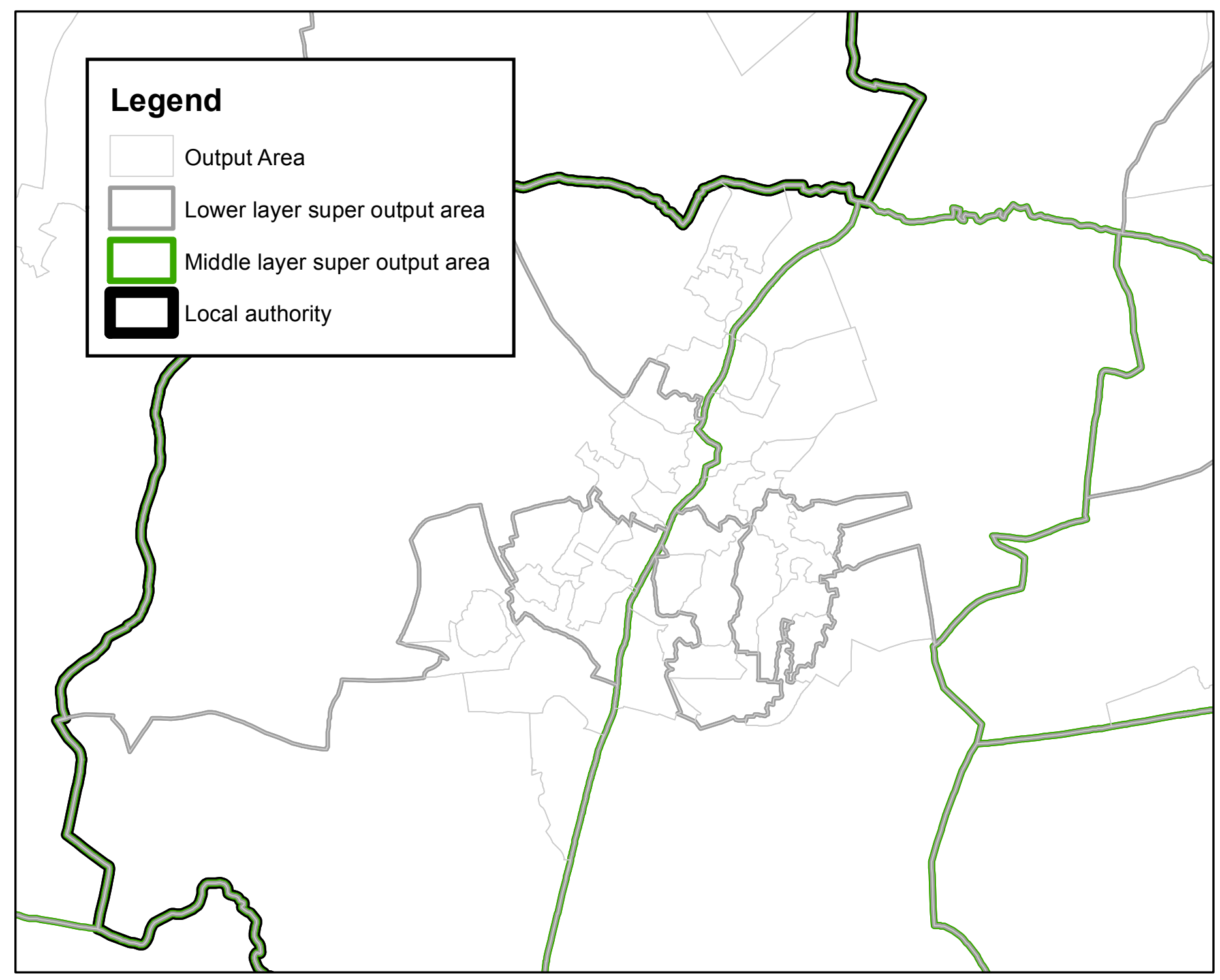




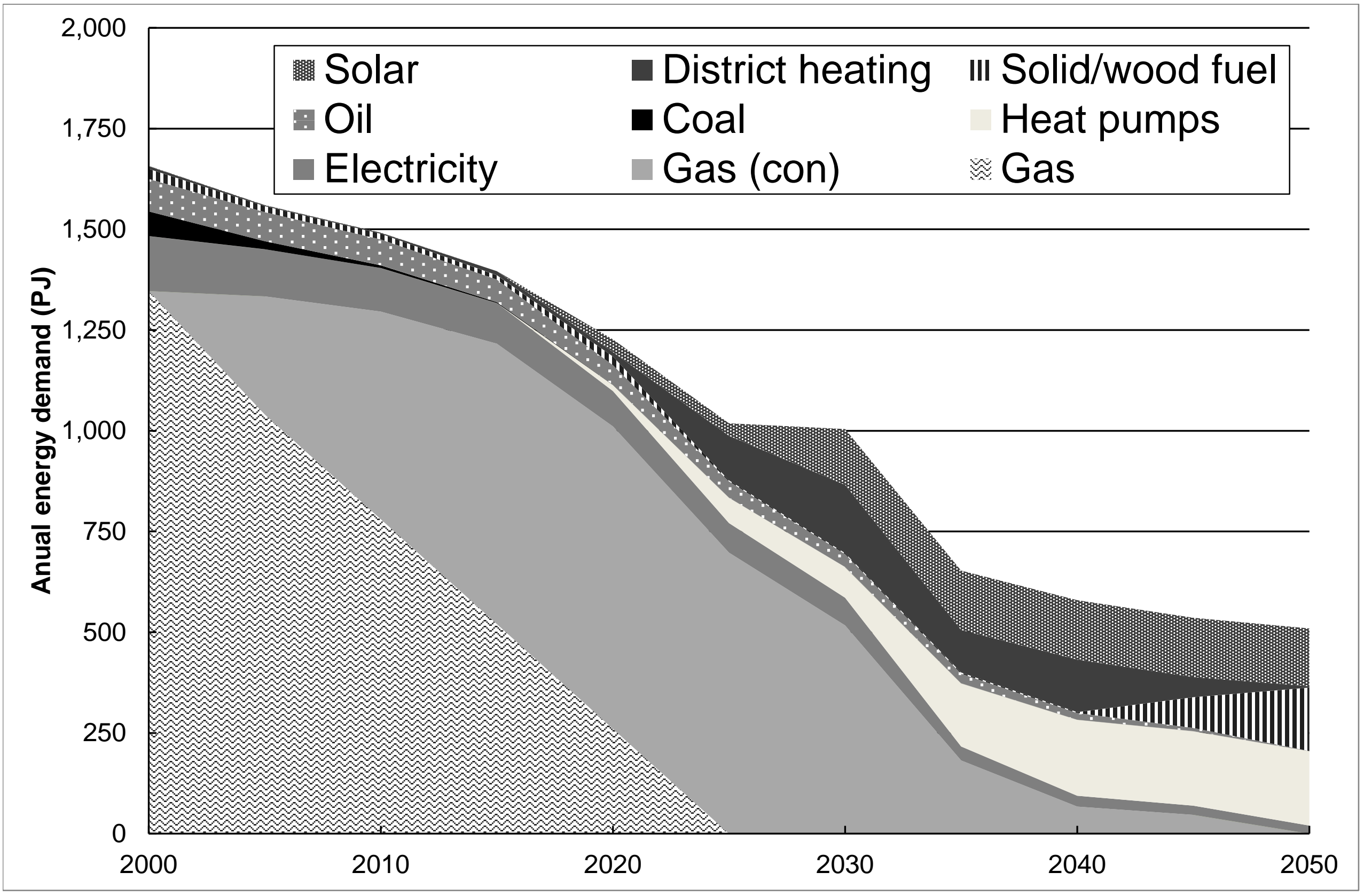




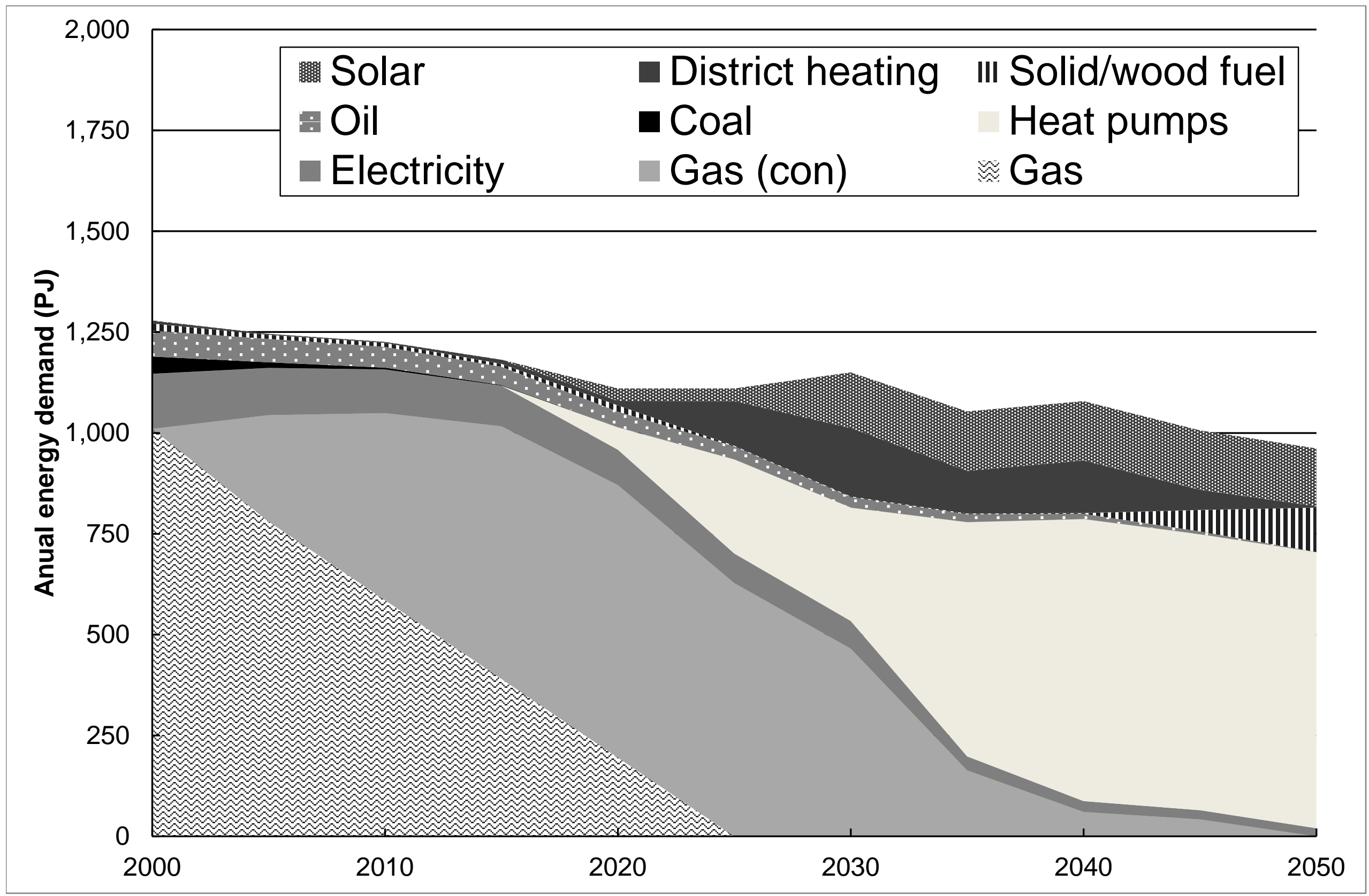




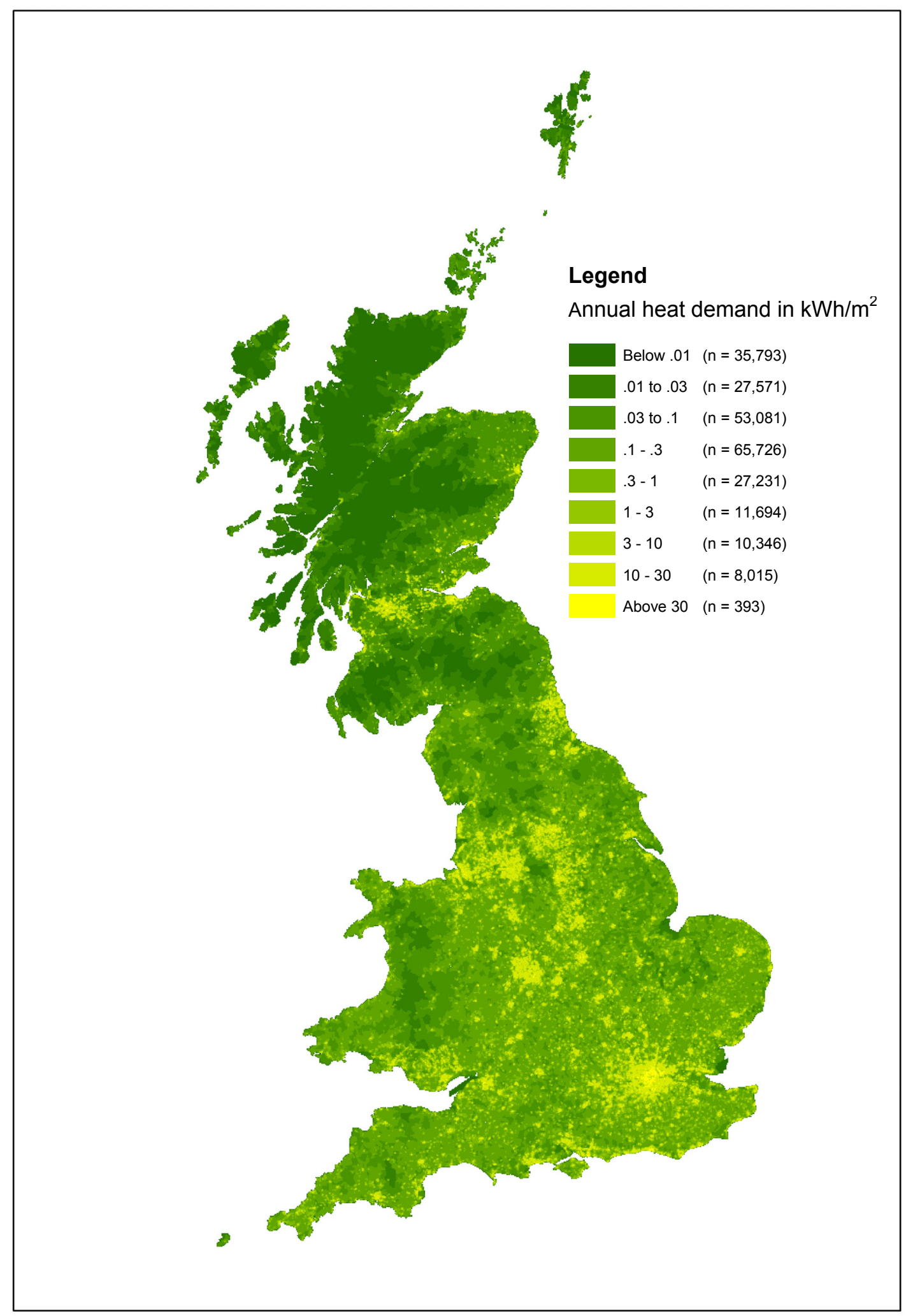




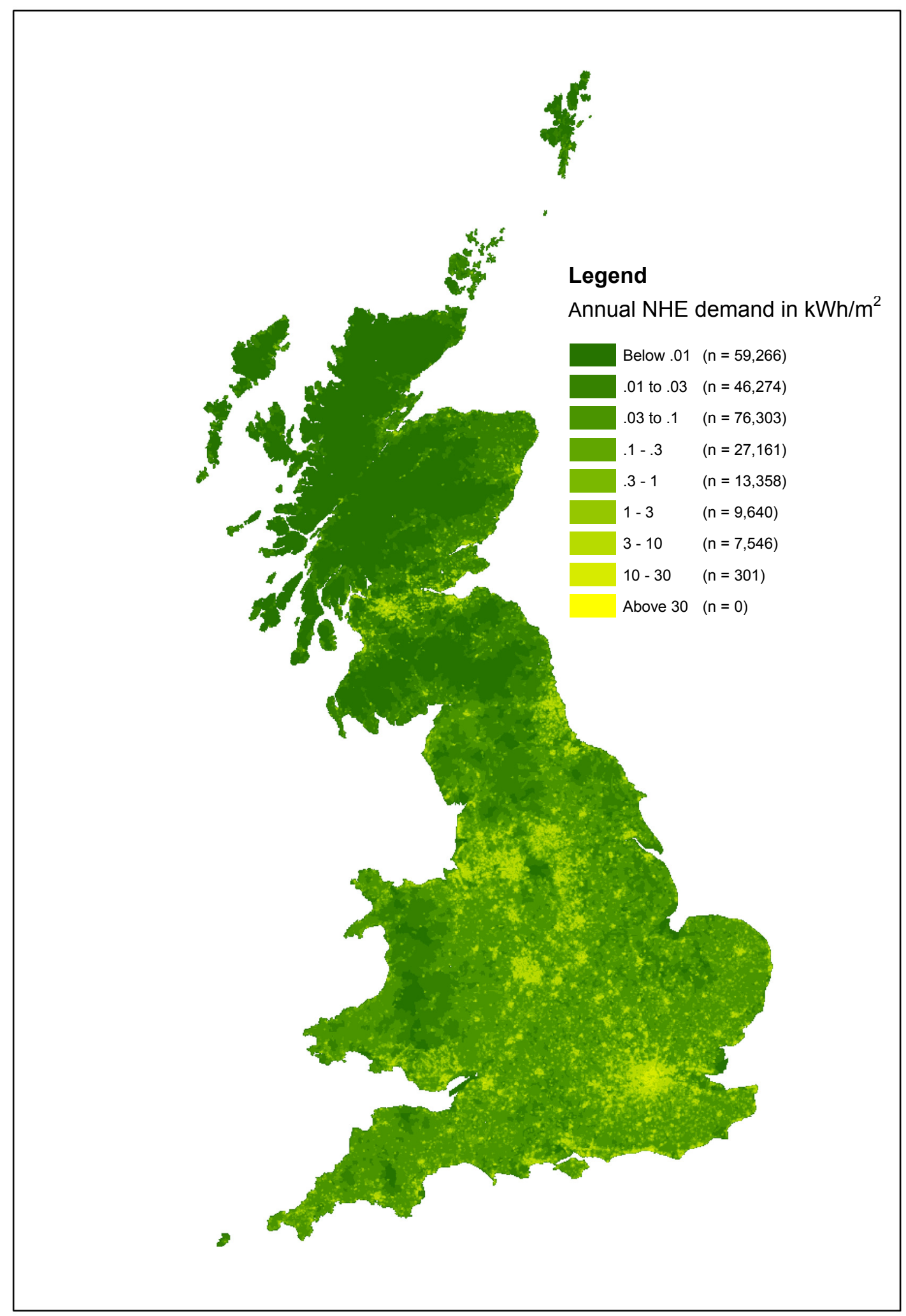




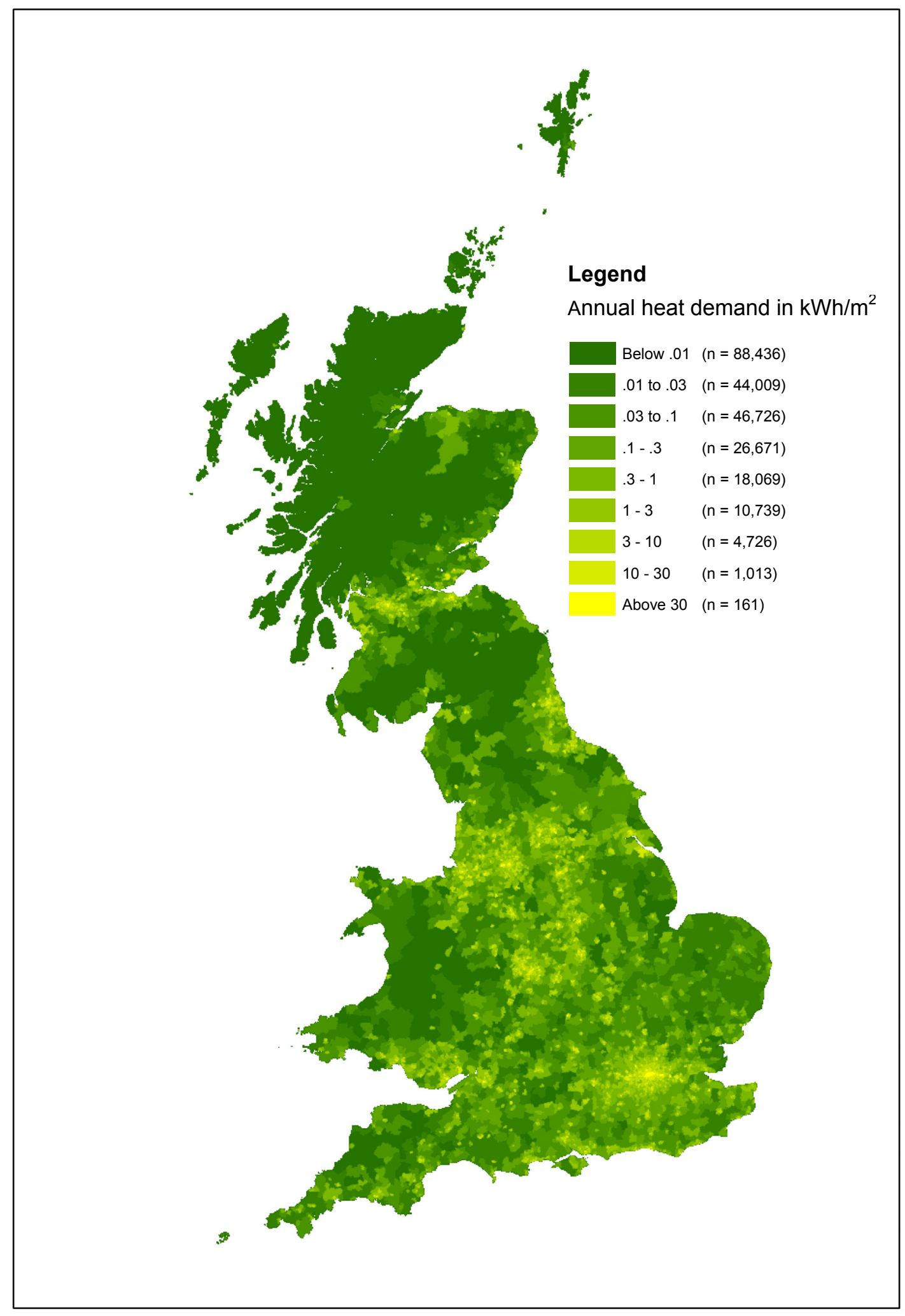




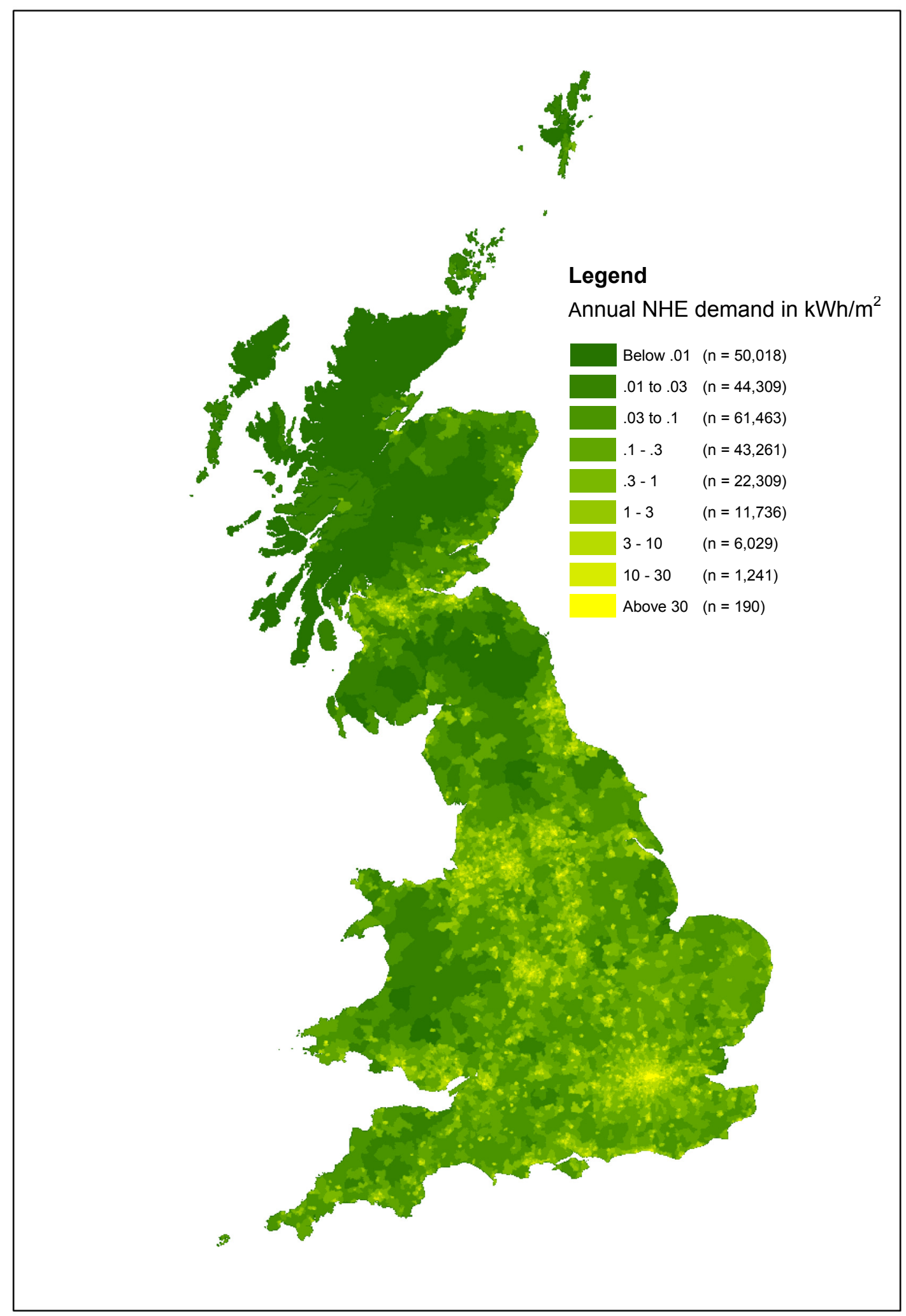

